\title{
Influence on a haemodinamic the paravertebral blockade at the open radical cistectomy
}

Kananchuk S. ${ }^{1}$, llukevich $\mathrm{G} .{ }^{2}$

${ }^{1}$ Republican Clinical Medical Center of the Administration of the President of the Republic of Belarus, Minsk, Belarus

\section{Belarusian Medical Academy of Post-Graduate Education, Minsk, Belarus}

Introduction: Among all malignant neoplasms of the urinary tract, the leading third place steadily occupies bladder cancer (BC). The standard of treatment of patients with musculo-invasive BC, with multiple bladder tumors or with all-wall lesions, as well as with bladder cancer without muscular invasion with unfavorable prognosis, is radical cystectomy (RCE) with urinary diversion.

In modern clinical practice, most often RCE is performed under general anesthesia in combination with neuraxial blockades: epidural or spinal. These types of regional blockades most effectively suppress nociceptive impulses, however, in connection with the development of the effect of desympatization, they can cause pronounced hemodynamic fluctuations in arterial pressure. In connection with this adverse effect in recent years, an increasing preference is given to the use in the abdominal surgery of the paravertebral blockade.

Background and Goal of Study: security impact assessment of paravertebral blockade on hemodynamics during radical cystectomy.

Materials and Methods: On the basis of the N.N. Alexandrov National Cancer Centre of Belarus from 2013 of 2016 was carried out a prospective randomized study with an analysis of anesthetic management of radical cystectomy in 107 patients with the bladder cancer (88 men and 19 women) mean age $62,5 \pm 9,1$. All patients used a general endotracheal anesthesia (GA) with regional blockade. The investigated patients were divided into three clinical groups depending on the type of regional anesthesia used (randomization of patients by clinical groups was performed by the random number method by Microsoft Excel for Windows 8): Gr1 ( $\mathrm{n}=36,33.6 \%$ of the total number of patients) - performed prolonged bilateral paravertebral blockade (PBPVB). Puncture and catheterization was performed at the level $\mathrm{Th}_{9}-\mathrm{Th}_{10}$; $\mathrm{Gr} 2(\mathrm{n}=35,32.8 \%)$ - prolonged epidural blockade (PEB), was performed at $\mathrm{Th}_{9}-\mathrm{Th}_{10}$; $\mathrm{Gr} 3(\mathrm{n}=36,33.6 \%)$ - combined spinal-epidural (CSEB) at two levels (epidural at $\mathrm{Th}_{9}-\mathrm{Th}_{10}$; spinal - at $\left.\mathrm{L}_{2}-\mathrm{L}_{3}\right)$. The groups were comparable to each other. See Table 1.

\section{Table 1. The characteristic of patients in the studied groups}

\begin{tabular}{|c|c|c|c|c|}
\hline \multicolumn{2}{|c|}{ Indicator } & $\begin{array}{c}\text { Group 1, n=36 } \\
\text { GA+PBPVB }\end{array}$ & $\begin{array}{c}\text { Group 2, n=35 } \\
\text { GA }+ \text { PEB }\end{array}$ & $\begin{array}{c}\text { Group 3, n=36 } \\
\text { GA+CSEB }\end{array}$ \\
\hline \multicolumn{2}{|c|}{ Gender, men/women, n (\%) } & $30(83,3 \%) / 7(16,7 \%)$ & $27(79,4 \%) / 7(20,6 \%)$ & $30(85,7 \%) / 5(14,3 \%)$ \\
\hline \multicolumn{2}{|c|}{ Age, $\mathrm{Me}[25 ; 75]$} & $62,5(56,0 ; 68,0)$ & $59,0(57,0 ; 67,0)$ & $61,5(54,0 ; 68,0)$ \\
\hline \multicolumn{2}{|c|}{ Body weight index, kg. Me $[25 ; 75]$} & $25,1(23,9 ; 28,9)$ & $24,5(21,7 ; 29,7)$ & $27,1(24,2 ; 30,6)$ \\
\hline \multicolumn{2}{|c|}{ Physical status on a scale ASA II-III / III-IV, n (\%) } & $27(75,0 \%) / 9(22,9 \%)$ & $27(79,4 \%) / 7(20,6 \%)$ & $27(77,1 \%) / 8(22,9 \%)$ \\
\hline \multicolumn{2}{|c|}{ Risk of anesthesia on AAA II-III / III-IV, n (\%) } & $29(88,6 \%) / 7(11,4 \%)$ & $28(91,2 \%) / 3(8,8 \%)$ & $27(91,4 \%) / 3(8,6 \%)$ \\
\hline \multirow{3}{*}{$\begin{array}{l}\text { Type of } \\
\text { operation / } \\
\text { urinary } \\
\text { diversion }\end{array}$} & Ileocystoplasty to Hautmann, n (\%) & $17(47,2 \%)$ & $15(42,9 \%)$ & $16(44,4 \%)$ \\
\hline & Brikker's operation, n (\%) & $14(38,9 \%)$ & $14(40,0 \%)$ & $17(47,2 \%)$ \\
\hline & Bilateral cutaneous ureterostomy, n (\%) & $5(13,9 \%)$ & $6(17,1 \%)$ & $3(8,4 \%)$ \\
\hline \multicolumn{2}{|c|}{ Duration of surgical intervention, min, $\mathrm{Me}[25 ; 75]$} & $217,5(175 ; 245)$ & $215,0(195 ; 250)$ & $217,5(180 ; 240)$ \\
\hline
\end{tabular}

Adequacy of anesthesia throughout was evaluated in terms of mean blood pressure (MBP), heart rate (HR), in addition to the integrative assessment of blood pressure used the coefficients K1 end K2. R1-the ratio of the systolic blood pressure to the diastolic blood pressure and the K2-ratio diastolic blood pressure to pulse pressure. Normally, $\mathrm{K} 1=1,67 \pm 0,18$ units., $\mathrm{K} 2=1,60 \pm 0,49$ units. Allocate the following stages of the study: 1st - initial data (before surgery and anesthetic support); 2nd - before intubation; 3rd - after intubation; 4th - the beginning of the operation; 5th - 1 hour after the beginning of the operative intervention; 6th - the most traumatic stage of the operation, the 7th - the end of the operation, the 8th - 4 hours after the operation, the 9th - 24 hours after the operation.

At the end of the operation, a patient had a paravertebral or epidural catheter for continuous analgesia (up to 48-72 hours) and continuous infusion of a local anesthetic with a $0.2 \%$ solution of ropivacaine hydrochloride or a $0.125-0.25 \%$ solution of bupivacaine hydrochloride using a disposable elastomeric pump or infusomat. Statistical processing was performed using programs: the SPSS and Microsoft Excel for Windows 8.

\section{Results and Discussion:}

After 15,0 $\pm 4,3$ min after the start of surgery in all clinical groups noted gradual stabilization of the HR to stress-normal level. Marked reduction in HR was observed in 9 patients, which required the use of M-anticholinergics: in the Gr2 - 6 pers., in Gr3 - in 3, in Gr1 - was not required.

Analyzing the results of MAP, the obtained between the groups had statistically significant differences $(p \leq 0,05)$ between $\mathrm{Gr} 1$ and Gr2, between Gr1 and Gr3 groups, were obtained from the groups beginning with the 4th stage (Graph 1 ).
Between the groups on the map were statistically significant differences in the results ( $p \leq 0,05)$ between $\mathrm{Gr} 1$ and $\mathrm{Gr} 2$, between $\mathrm{Gr} 1$ and Gr3, starting with the 2nd stage, which required the use of inotropic support in the Gr2 - in 15 patients, and Gr3 - in 24. The indicators K1 and $\mathrm{K} 2$ were no significant differences between the groups, in $\mathrm{Gr} 3$ the values of $\mathrm{K} 2$ from the start of surgery there was a statistically significant increase compared to the norm.

\section{MBP Graph 1. Dynamics of mean blood pressure}

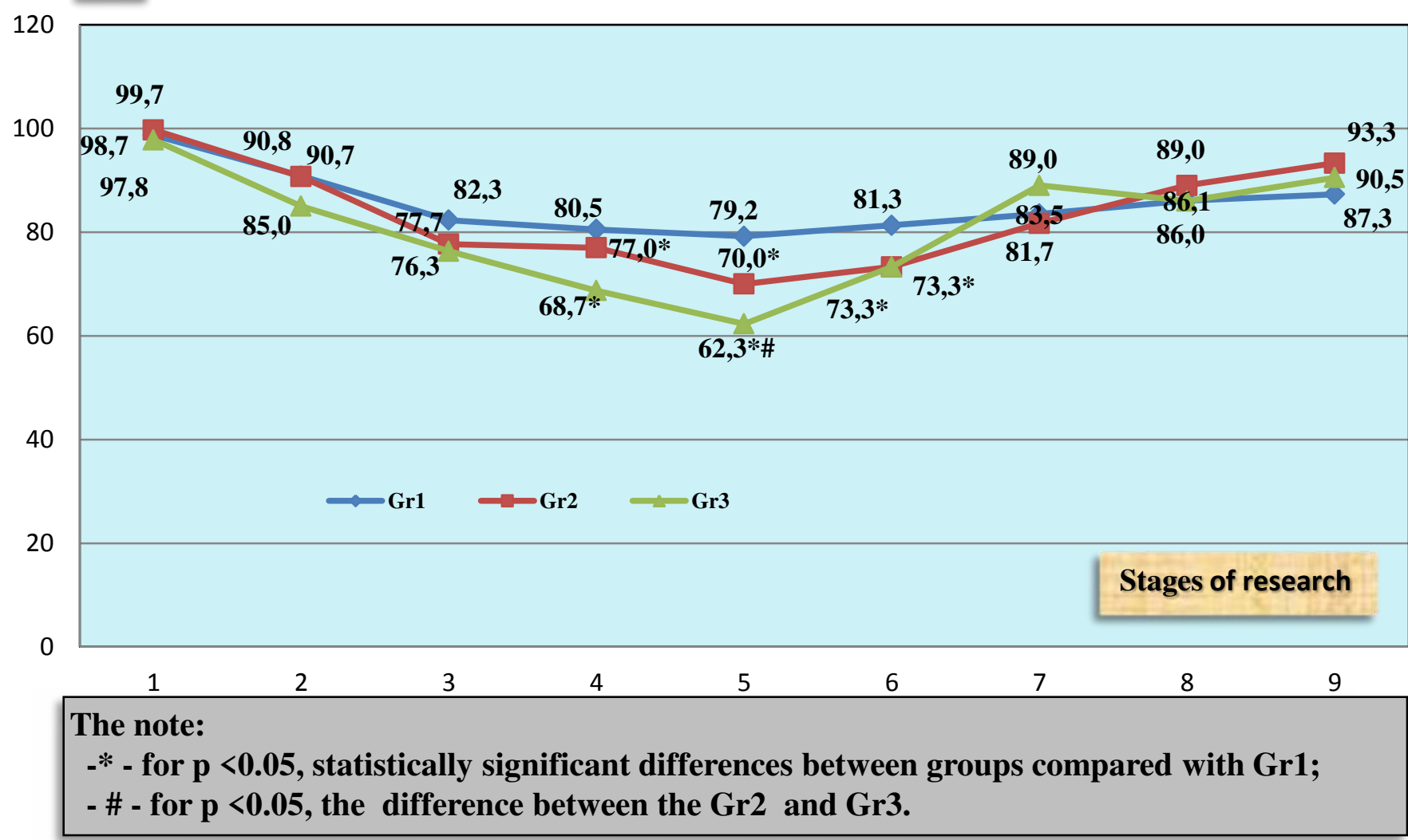

Conclusion(s): The use of paravertebral blockade at radical cystectomy effective method of anesthetic management, provides hemodynamic stability and is most appropriate in patients with concomitant diseases of the cardiovascular system. 